\title{
Pollution prevention and sustainable future
}

\author{
Eldon Raj Rene ${ }^{1} \cdot$ Li Shu $^{2,3} \cdot$ Veeriah Jegatheesan ${ }^{4}$
}

Published online: 14 January 2022

(c) The Author(s), under exclusive licence to Springer-Verlag GmbH Germany, part of Springer Nature 2021

This special issue contains 7 articles that are disseminating the physical, chemical and biological process techniques and tools for pollution prevention and sustainability. They are selected from the presentations made at the 13th annual international conference on the "Challenges in Environmental Science and Engineering", CESE-2020 that was held online on the 7th and the 8th of November 2020. There were 177 delegates from 18 countries and regions participated in CESE-2020. This special issue covers the removal of chemical species such as phosphorus from water and related effects, recovery of chemical species such as copper and nickel, carbon capture using activated carbon, utilization of hydrogels, detection technology and inverter technology.

One article on chemical species removal discusses about fixed-bed column dynamics of ultrasound and Na-functionalized diatomite (U-D-Na) to remove phosphate from water. The U-D-Na was functionalized by the inexpensive $\mathrm{NaCl}$ reagent after simple ultrasonic purification of diatomite. The maximum removal rate of phosphate was found to be more than $95 \%$, and a thrice loop of effective regeneration was achieved with $0.1 \mathrm{M}$ hydrochloric acid eluent and deionized water. Therefore, the authors concluded that the U-D-Na could be used as a better alternative phosphate adsorbent for wastewater in a continuous column sorption process. The next article on chemical species removal discusses the reduction of $\mathrm{N}_{2} \mathrm{O}$ generation during denitrifying phosphorus removal with propionate as carbon source

Responsible Editor: Philippe Garrigues

Veeriah Jegatheesan

jega.jegatheesan@rmit.edu.au

1 UNESCO-IHE Institute for Water Education, Westvest 7, 2611 AX Delft, The Netherlands

2 School of Engineering, Edith Cowan University, 70 Joondalup Drive, Joondalup, Perth, WA 6027, Australia

3 LJS Environment, 2 Parkville Avenue, VIC 3052 Parkville, Australia

4 School of Engineering and Water: Effective Technologies and Tools (WETT) Research CentreRMIT, University Melbourne, VIC 3052 Melbourne, Australia in sequencing batch reactors. The study found that the nitrogen removal was $40.6 \%$ lower when propionate was used as the carbon source instead of acetate, while phosphorus removal was similar. Enrichment of glycogen-accumulating organisms in the acetate system suggested to cause higher $\mathrm{N}_{2} \mathrm{O}$ production in the acetate system. The lower nitrite accumulation in the propionate system compared to the acetate system was found to be the dominant factor leading to the lower $\mathrm{N}_{2} \mathrm{O}$ production. The article on recovery deals with the competitive effect of copper and nickel recovery with carbonate in the fluidized-bed homogeneous granulation process (FBHGP). It aims to recover copper and nickel from the wastewater originating from printed circuit boards (PCB) processes using a FBHGP. FBHGP is an advanced green technology that removes copper and nickel and transforms the sludge into a hard granule. The study found that the copper has been successfully recovered from synthetic PCB wastewater using FBHGP. However, the nickel needs a multi-step fluidized bed reactor.

The article on hydrogels focusses on the shape stable poly(vinyl alcohol) (PVA) hydrogels with immobilized metal hexacyanoferrates for radioactive caesium removal from waters. The metal hexacyanoferrates with transition metal ions to replace ferric ions in the face-centred cubic structure of Prussian blue (PB) crystals (a total of eight $\mathrm{PB}$ analogue particles in two families $\mathrm{M}_{3}\left[\mathrm{Fe}(\mathrm{III})(\mathrm{CN})_{6}\right]_{2}$ (MFe(III)) or $\mathrm{M}_{4}\left[\mathrm{Fe}(\mathrm{II})(\mathrm{CN})_{6}\right]_{2}$ (MFe(II)) with $\mathrm{M}=\mathrm{Zn}, \mathrm{Ni}$, $\mathrm{Cu}$, or $\mathrm{Co}$ synthesized in this study) are candidate adsorbents for caesium ions. The PVA-CoFe(III) was found to be the best candidate for enhanced Cs removal. The article on carbon capture investigates the production and characterization of bamboo-based activated carbon through single-step $\mathrm{H}_{3} \mathrm{PO}_{4}$ activation for $\mathrm{CO}_{2}$ capture. A single-stage phosphoric acid $\left(\mathrm{H}_{3} \mathrm{PO}_{4}\right)$ activation is adopted at a constant temperature and holding time. The prepared activated carbon via $50 \mathrm{wt} \%$ $\mathrm{H}_{3} \mathrm{PO}_{4}$ activation shows the highest BET surface area and carbon dioxide $\left(\mathrm{CO}_{2}\right)$ adsorption capacity of $1.45 \mathrm{mmol} \mathrm{g}^{-1}$ at $25^{\circ} \mathrm{C} / \mathrm{bar}$ and $9.0 \mathrm{mmol} \mathrm{g}{ }^{-1}$ at $25^{\circ} \mathrm{C} / 30$ bar.

The article on detection technology investigates a new electrode constructed via the anodic electropolymerization of poly-(L-serine) (PLS) on a reduced graphene oxide 
(rGO) - Nafion-modified glassy carbon electrode (GCE) for the detection of the emerging organic contaminant naproxen (NPX). The synergistic effect of PLS and rGO - Nafion was found to facilitate the catalytic oxidation of NPX on PLS/ rGO - Nafion/GCE greatly. The modified electrode exhibited excellent linearity with respect to NPX concentration in the range of 4.3 to $87 \mu \mathrm{M}$, and the limit of detection was $0.23 \mu \mathrm{M}$.

The article on inverter technology elaborates the CC-LA: Determining Optimal Switching Angles in Cascaded H-bridge Multilevel Inverter with the aid of Binary Cat Cubpool-based Lion Algorithm. The objective of optimizing the switching angle is to generate the needed fundamental voltage and minimize the harmonic content.

The guest Editors of this special issue are thankful to the Editor-in-Chief of Environmental Science and Pollution Control Journal, Professor Garrigues, and the publishing editor Alexandrine Cheronet for providing an opportunity to publish selected peer-reviewed papers that were presented at CESE-2020. Thanks are also due to Ms. Fanny Creusot, Editorial Assistant, and the entire production team of the journal for their valuable support in bringing out this issue successfully. Last but not least, our sincere appreciation to all the reviewers for their invaluable and critical review comments on manuscripts that were submitted for this special issue.

Publisher's note Springer Nature remains neutral with regard to jurisdictional claims in published maps and institutional affiliations.

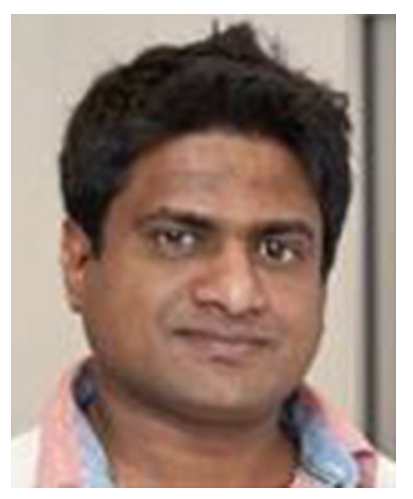

Eldon Raj Rene is a senior lecturer of Resource Recovery Technology at UNESCO-IHE, Institute for Water Education (Delft, the Netherlands). His research majorly focuses on the development of biological treatment processes for wastewater and waste gas treatment, nonpoint source pollution prevention, resource recovery from waste gases, the use of artificial intelligence tools for environmental monitoring, environmental process control and ecoindustrial parks. He has authored two books on Sustainable Heavy Metal Remediation (Vols. 1 and 2, published in 2017 by Springer), and he currently serves as the managing editor for Reviews in Environmental Science and Bio/Technology (Springer) and as an associate editor of the Journal of Environmental Engineering (ASCE-JEE). He is also the two-time recipient of the Young Scientist Award conferred by the Challenges in Environmental Science and Engineering conference organizers in Sydney (Australia) and Kaohsiung (Taiwan), respectively. In 2007, he was awarded the Juan de la Cierva fellowship by the Ministry of Science and Innovation
(Spain). Eldon has also edited special (thematic) issues and volumes in the following journalsBioresource TechnologyInternational Biodeterioration \& BiodegradationJournal of Environmental ManagementASCE-Journal of Environmental EngineeringJournal of Hazardous Materials and Environmental Science and Pollution Research. He is a life member at the International Bioprocessing Association (IBA). He is the co-chair of the following international conference series: Challenges in Environmental Science and Technology (CESE), Research Frontiers in Chalcogen Cycle Science \& Technology (G16) and Alternative Fuels, Energy and Environment (ICAFEE). As a part of his capacity building initiative, Eldon regularly conducts scientific writing and skill development workshops at major international conferences/ meetings, as well as for students from developing countries.

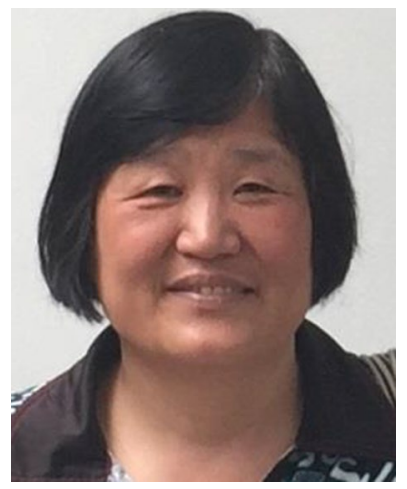

Dr. LiShu is the Managing Director of LJS Environment, Australia, adjunct Associate Professor at Edith Cowan University, Australia and a Guest Professor at Shandong Normal University, China. Shu has more than 200 publications in forms of Book, Book Chapters, Journal Papers and Refereed Conference papers. She obtained her Bachelor degree from Qingdao University of Science and Technology, China; Master degree from Asian Institute of Technology, Thailand; and $\mathrm{PhD}$ from University of New South Wales, Australia. She with her students and colleagues is the first to document images of water clusters taken by a microscope and published a paper titled "The structure of water" in 2020. The research group reported that $\mathrm{pH}$ of neutral salt was not 7 and the neutral salt was corrosive. Dr. Li Shu proposed that strong electrolyte such as $\mathrm{NaCl}$ existed in water as aggregates in 2005. The concept has been supported using a Nanosizer (Malvern), and results were published in 2013 and 2017. Li Shu's research interest is in water and wastewater treatment using membrane filters, resource recovery and zero liquid discharge. Various membranes and nanoparticles have been employed for water and wastewater reclamation. She taught Water and Wastewater Systems to undergraduate and post-graduate students. She is one of the founders of an International Conference "Challenges in Environmental Science and Technology", CESE, and has been the CoChair of the Conference since 2008. She is an Editorial Board Member of Austin Environmental Sciences and SM Journal of Environmental Chemical Engineering. She is a guest editor of the following journalsBioresource Technology; Desalination and Water Treatment; International Biodeterioration and Biodegradation; Water, Air and Soil Pollution: Focus; Reviews in Environmental Science and Bio/Technology; and Membrane Water Treatment.

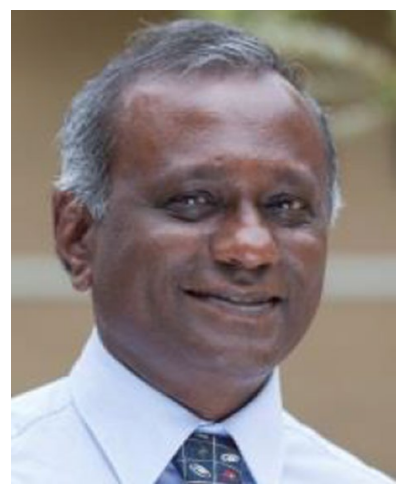

Veeriah Jegatheesan (Jega) is a Professor of Environmental Engineering and the Director of Water: Effective Technologies and Tools (WETT) Research Centre at RMIT University, Melbourne, Australia. Jega is the founder and Chairman of the international conference series on Challenges in Environmental Science \& Engineering (CESE) held annually since 2008. Jega has conducted extensive research on the application of membrane 
bioreactors, sugar cane juice clarification, sea water desalination and the treatment of mine tailing ponds. He has over 450 publications including more than 170 peer-reviewed journal articles and five edited books. Jega is also the managing guest editor of 40 special issues in peer-reviewed journals. In 2019, Stormwater Industry Association (Australia) has appointed him as one of the Governance Panel members for the Australian Stormwater Quality Improvement Device Evaluation
Protocol (SQIDEP). Jega is the Editor-in-Chief of a book series entitled Applied Environmental Science and Engineering (AESE) for a Sustainable Future published by Springer and has been instrumental for publishing 12 books since 2015. Jega has been appointed as the Editor-inChief of Environmental Quality Management journal (Wiley Publisher) from January 2020. 